\title{
RESEARCH \\ An Ordered Yeast Artificial Chromosome Library Covering Over Half of Rice Chromosome 6
}

\author{
Yosuke Umehara, Hiroshi Tanoue, Nori Kurata, ${ }^{1}$ Ikuo Ashikawa, \\ Yuzo Minobe, and Takuji Sasaki
}

\author{
Rice Genome Research Program, National Institute of Agrobiological Resources/Society for \\ Techno-innovation of Agriculture, Forestry and Fisheries, Tsukuba, Ibaraki 305 Japan
}

\begin{abstract}
Yeast artificial chromosome (YAC) clones carrying DNA marker sequences located on the rice genetic map of chromosome 6 were ordered for physical mapping. A total of 122 restriction fragment length polymorphism markers, 16 sequence-tagged site markers, and five random amplified polymorphic DNA markers located, on average, at 0.9-cM intervals, were used for YAC clone screening by colony/Southern hybridization and PCR screening, respectively. A total of 216 individual YACs were selected from our YAC library of 7000 clones covering six genome equivalents. Each DNA marker could select, on average, 4.8 YAC clones, with 11 clones being the maximum. The YACs localized to the corresponding linkage map positions form 43 contigs and encompass about $60 \%$ of rice chromosome 6 . This is the first step in constructing a physical map covering the whole rice genome by chromosome landing with YAC clones. These YACs and data will be used soon to isolate phenotypical trait genes by map-based cloning.
\end{abstract}

Rice is one of the most important crops in the world and a most suitable plant for genome analysis for several reasons. First, it has the smallest genome, $4.3 \times 10^{8} \mathrm{bp}$, of the cereal crops (Arumuganathan and Earle 1991). Second, several condensed genetic linkage maps with DNA markers have already been constructed (Saito et al. 1991; Causse et al. 1994; Kurata et al. 1994b). Third, its classical genetic map consists of more than 150 trait markers (Kinoshita 1993). Fourth, a yeast artificial chromosome (YAC) library has already been constructed (Umehara et al. 1995). Fifth, transformation and regeneration systems are established in several varieties. Finally, synteny between rice and other cereals (wheat, barley, and maize) has been revealed by reciprocal mapping with DNA markers (Ahn et al. 1993; Ahn and Tanksley 1993; Kurata et al. 1994a). Across many diverse cereals, not only are the orders of DNA markers conserved, but also the positions of genetic traits (Paterson et al. 1995). The genetics of other cereals, such as barley, wheat, and maize, have been studied extensively, but their genome sizes are much larger than that of

'Corresponding author. E-MAIL kuratan@abr.affrc.go.jp; FAX 81-298-38-7468. rice (Arumuganathan and Earle 1991). Recent studies showed that genome structures are well conserved between rice and barley or wheat, even at the several-hundred-kb resolution of YAC clones (Dunford et al. 1995; Kilian et al. 1995). These characteristics have made rice a model plant for cereal genetics (Moore et al. 1993). Therefore, genome analysis of rice is important for studying other cereals, too. Construction of a rice genome physical map will be a great advance in analyzing the genome organization of rice, as well as those of other cereal crops.

A physical map is essential to unravel the genome structures of organisms and to isolate trait genes by map-based cloning. One of the main aims of our Rice Genome Research Program is to make ordered genomic clone libraries along all 12 rice chromosomes. In genome analysis of Arabidopsis thaliana, the model of higher plants, $90 \%$ of the genome was covered with 750 contigs with 20,000 cosmid clones (Hauge et al. 1991). YAC contigs are now being constructed to cover the whole genome of Arabidopsis (Schmidt and Dean 1992). Recently, it was reported that a physical map of chromosome 4 was constructed with YAC clones and used to analyze the organization of the chromosome (Schmidt et al. 1995).

Our program constructed a YAC library cov- 


\section{UMEHARA EI AL.}

ering about six genome equivalents to develop a rice physical map (Umehara et al. 1995). The genome size of rice, although small compared with those of most other higher plants, is still very large. To cover efficiently such a large genome with DNA clones, it is necessary to use a system capable of cloning long DNA fragments of several hundreds of $\mathrm{kb}$ in length, such as YACs. We chose the chromosome landing method using all the DNA markers on our high-density molecular linkage map (Kurata et al. 1994b) to order the YAC clones. We have located 1383 DNA markers dispersed, on average, every $300 \mathrm{~kb}$ in the rice genome.

In this report, we describe the first stage of YAC contig building along the genetic linkage map of rice chromosome 6 . The genetic distance of this chromosome was calculated to be 130.4 $\mathrm{cM}$ in our linkage map (Kurata et al. 1994b). From this value, the size of chromosome 6 was estimated approximately $36 \mathrm{Mb}$ from proportional dissection of the rice genome (130.4 cM/ $1575 \mathrm{cM} \times 430 \mathrm{Mb}=36 \mathrm{Mb}$ ). The total of 156 DNA markers mapped on this chromosome disperse an average of $230 \mathrm{~kb}$ apart from each other. Chromosome 6 should be the first target of physical mapping in rice, because the largest number of important phenotypical trait genes are located on it. Some of these traits are genes of agronomical importance and also of biological interest, for example, glutinous endosperm gene $w x$, Hybrid sterility gene $S-5$, photosensitivity gene Se-1, and Pyricularia oryzae resistance genes $\mathrm{Pi}-\mathrm{Z}$ and $\mathrm{Pi}-\mathrm{Z}^{t}$ (Kinoshita 1993). Therefore, the ordered YAC clone library presented here will supply important information both on physical structure and for positional cloning of trait genes on this chromosome.

\section{RESULTS}

\section{Colony and Southern Hybridization of YAC Clones with Mapped DNA markers}

A total of 125 DNA markers on chromosome 6 were used for selecting YAC clones by colony hybridization and hybridized to 1043 colonies. All of these candidate clones were detected by Southern hybridization of each genomic DNA band that was used for restriction fragment length polymorphism (RFLP) mapping. Sixty-six out of 125 DNA markers detected only one genomic fragment. YAC clones carrying single-copy se- quences were readily identified (for example, see Fig. 1A). In contrast, 59 out of 125 RFLP markers on chromosome 6 detect multiple fragments. For example, the DNA marker C288 (Fig. 1B) could identify YACs carrying the sequence located on both chromosome 6 and other chromosomes. Further, among the multiple fragments detected by the 59 probes, only a subset can be mapped as RFLP markers. In contrast, many more fragments can be mapped using YACs. The multiple-copy DNA marker V19 hybridized (Fig. 1C) not only with YACs that had sequences located on chromosome 6 but also with YACs carrying sequences that have not been yet mapped on the linkage map because of the lack of detectable polymorphism between the parental rice strains. However, there were many similar cases in which unmapped sequences (like the 2.6-kb and $1.2-\mathrm{kb}$ EcoRV fragments in Fig. 1C) also were found to be located on chromosome 6 , because these copies were contained in the same YAC clones together with the copies already mapped on chromosome 6. Assignment of each copy of these multiplecopy RFLP markers to YACs thus presents useful information about the distributions of multiple copies of highly homologous DNA sequences in the rice genome, especially for multigene families of expressed sequences.

On chromosome 6, five RFLP markers (C425B, V19B, Y2668LB, C709C, G2028) were mapped by scoring only for Kasalath dominant markers with no discernible allele of Nipponbare (Nipponbare and Kasalath are two parent varieties used for our high-density genetic mapping). However, Southern hybridization with these markers could, in most cases, detect DNA signals of the Nipponbare alleles for C425B, C709C, G2028, and in the selected YAC clones.

\section{YAC Screening with Random Amplified Polymorphic DNAs and STS Markers}

Chromosome 6 has been typed for 26 random amplified polymorphic DNAs (RAPDs) denoted as $P$ markers and 3 sequence-tagged site (STS) markers denoted as T markers. The mapped fragments of 13 RAPD markers were cloned and transformed to STS markers (Monna et al. 1994, 1995). The STS marker primers produced specific fragments when using the corresponding YAC clones pooled in the PCR screening. All 3 T markers and the $13 \mathrm{P}$ markers out of 26 RAPDs on chromosome 6 could identify the corresponding YAC clones using the 3-D PCR screening system. 
A

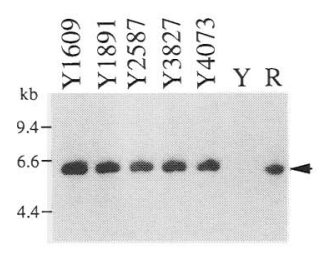

B

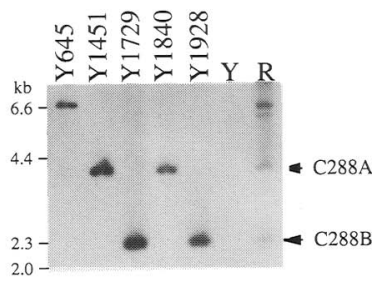

C

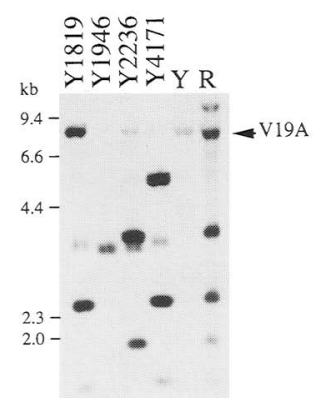

Figure 1 Southern hybridization of YACs to detect mapped RFLP bands. The DNAs of candidate YAC clones (lanes Y1609, Y1891, Y2587, Y3827, and $\mathrm{Y} 4073$ in $A, \mathrm{Y} 645, \mathrm{Y} 1451, \mathrm{Y} 1729, \mathrm{Y} 1840$, and $\mathrm{Y} 1928$ in $B, Y 1819, Y 1946, Y 2236$, and $Y 4171$ in C) selected by colony hybridization, rice Nipponbare DNA (lane R) and yeast $S$. cereviseae DNA of strain $A B 1380$ (lane $Y$ ) were digested with endonucleases and blot-analyzed by hybridization with RFLP probes. The arrowheads point to the DNA fragments mapped on the linkage map. Molecular weights indicated on left. Probe labeling and signal detection were performed with an ECL system (Amersham). (A) Southern hybridization image with a single-copy probe, R2147. DNAs were digested with Bglll. Arrowhead shows DNA signals for the hybridization of the R2147 marker. (B) Southern hybridization image with a multiple-copy probe, C288. DNAs were digested with Kpnl. Arrows: C288A, 3.8-kb Kpnl fragment mapped to chromosome 5 as a locus of C288A; C288B, 2.3-kb Kpnl fragment mapped to chromosome 6 as a locus of C288B. (C) Southern hybridization image with a multiple-copy probe, $V 19$. DNAs were digested with EcoRV. The 8-kb EcoRV fragment detected by V19A was mapped on chromosome 6 as the V19A locus. Because it carries this 8-kb fragment, YAC clone $\mathrm{Y} 1819$ was mapped on the $\mathrm{V} 19$ site of chromosome 6. Y4171 was mapped on this site because it shares $2.6-\mathrm{kb}$ and $1.2-\mathrm{kb}$ fragments with Y1819. The largest fragment of $Y 4171$ might be carrying V19A, but it gets smaller because this fragment locates in the end of the Y4171 insert. The Y1946 and Y2236 YACs were not mapped on chromosome 6 because they do not hold 8-kb EcoRV fragments and do not share any rice fragments with the YAC clones mapped on this site.
AN ORDERED YAC LIBRARY OF RICE CHROMOSOME 6

Of the remaining 13 RAPD markers, five of the cloned RAPD fragments could detect YAC clones through hybridization of the total PCR product in each pool with the cloned DNA fragments.

\section{Chromosome Landing of YAC Clones on Chromosome 6}

A total of 216 distinct YAC clones were confirmed to be located on the 101 RFLP, 16 STS, and 5 RAPD marker positions on chromosome 6 (Fig. $2)$. YAC contigs were connected by $>2$ DNA marker positions (as shown by thick lines in Fig. 2 ) in 21 regions. Twenty-two other YAC contigs were located alone at single DNA marker positions. Therefore, the 216 YAC clones comprised 43 contigs.

The single YACs containing the highest number of six markers were Y1525, Y1250, and Y4203, which span $0.3,0.2$, and $3.0 \mathrm{cM}$, respectively. These YACs are near the bottom end of chromosome 6 . The longest contig covers $4.8 \mathrm{cM}$ from P108 to P123 in the region 2. Minimal tiling path together with singly located YACs on this chromosome consist of only 63 YACs of various sizes (Fig. 2).

Each DNA marker selected 4.8 clones, on average, and G1314A identified the maximum of 11 clones. Multiple-copy DNA markers selected 43 clones on other chromosomes, and 130 clones carrying other copy sequences that have not yet been mapped on any chromosomes because of the lack of polymorphism.

Twenty-two RFLP markers could not identify any YACs located on the corresponding positions (represented by open-face type in Fig. 2). Those markers were mapped on 12 regions. No YAC clones could be identified with clustered multiple DNA markers on the 0.3-cM region from R2291 to $\mathrm{R} 2749$ in region 1 and the $3.1-\mathrm{cM}$ region at the bottom end of chromosome 6 .

Among the YAC clones selected with distinct markers, 47 YACs represented by open-face type in Figure 2 were shown to carry additional DNA markers mapped on other chromosomes or at positions farther than $10 \mathrm{cM}$ apart from the first markers. This result indicates that at least $22 \%$ of the identified YACs were chimeric.

\section{DISCUSSION}

One of the Rice Genome Research Program goals for the future is to reconstitute all 12 chromo- 


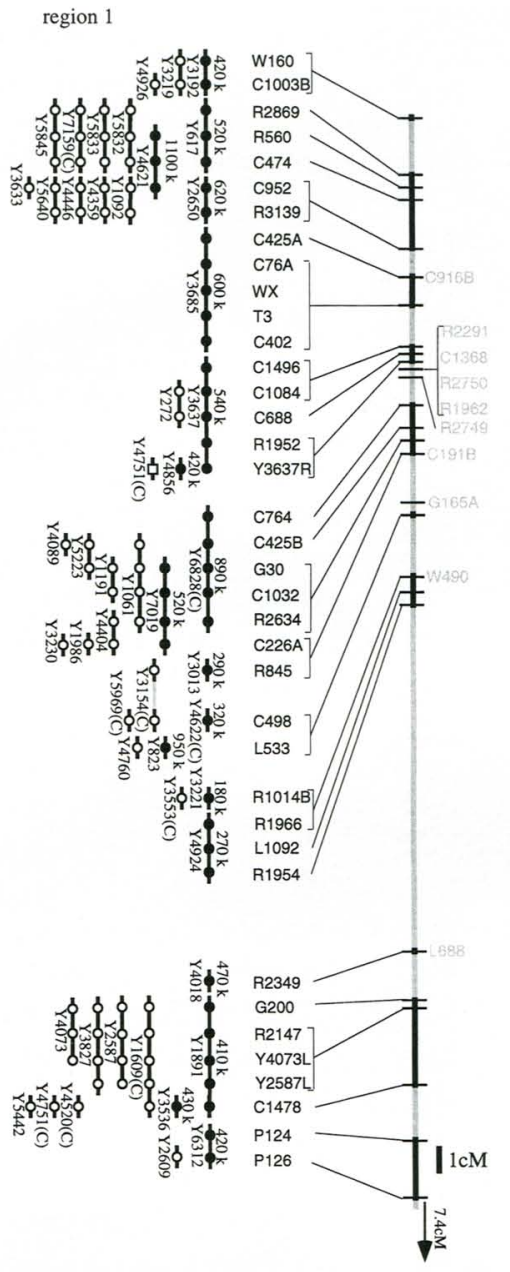

region 3 region 2

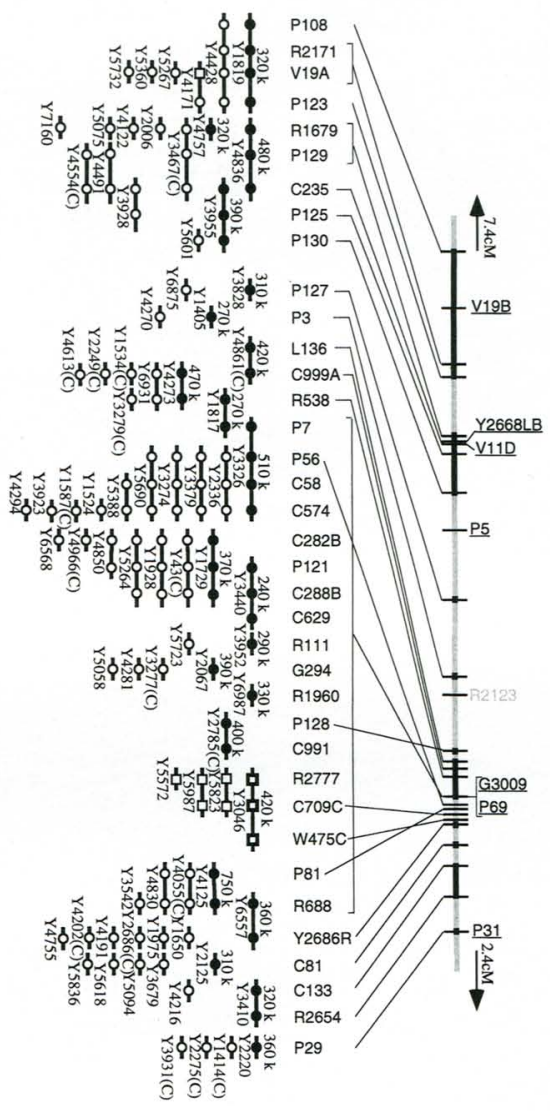

region 4

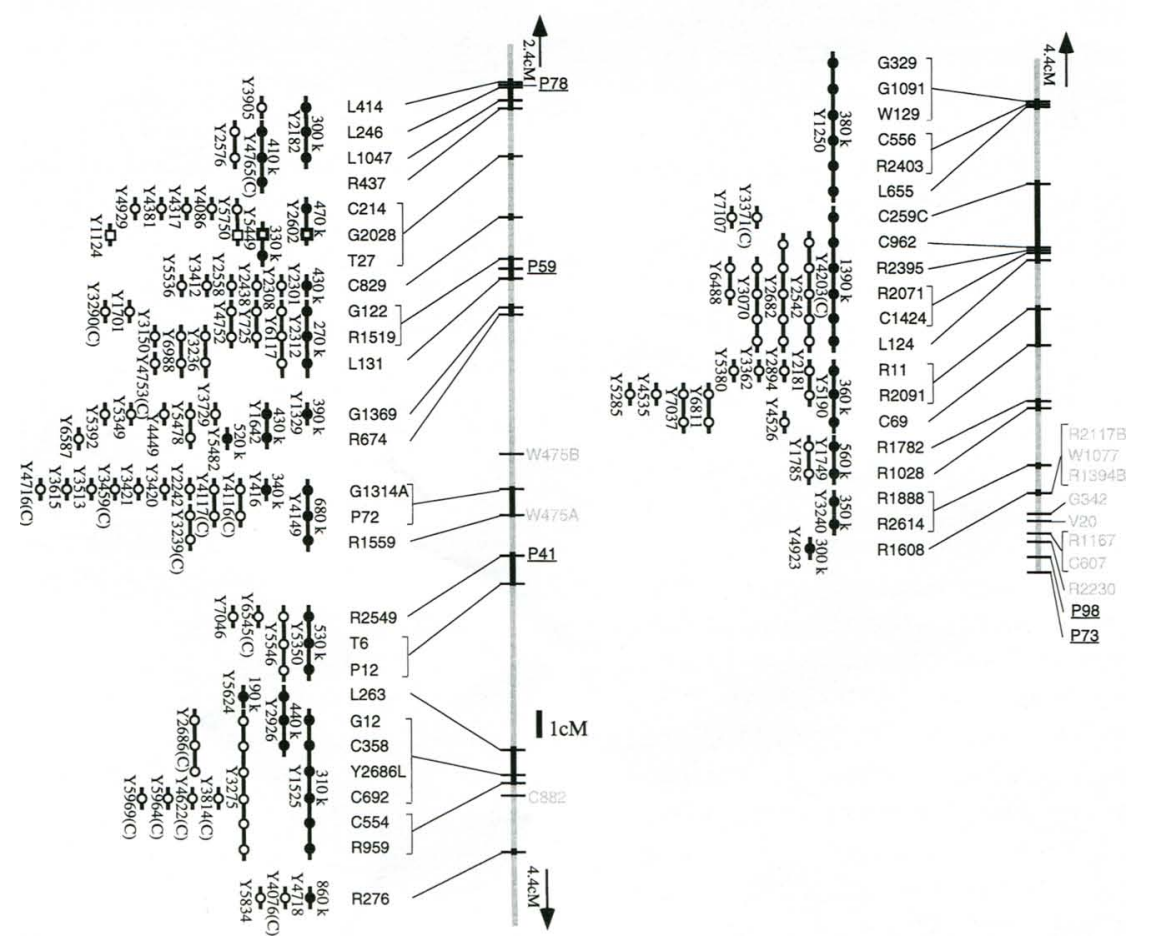

Figure 2 (See facing page for legend.) 
AN ORDERED YAC LIBRARY OF RICE CHROMOSOME 6

somes with ordered DNA clone libraries. In this study, we could cover over half of the whole length of chromosome 6 with long-insert YAC clones. A total of 119 markers could assign 216 YACs to chromosome 6 . The average number of YACs selected by one marker was 4.8 , lower than the number expected for the six rice genome equivalents covered by this library. The reason for this smaller number of YACs selected could be that some YAC clones contain organelle DNA and other clones carry only vectors. Some 216 distinct YACs on chromosome 6 were identified and distributed in 43 contigs. Twenty-two contigs cover only one DNA marker position on the linkage map. Assuming overlap of about $50 \%$ between neighboring YACs in these contigs, each single-marker position contig is estimated to cover $525 \mathrm{~kb}(350 \mathrm{~kb} \times 1.5=525 \mathrm{~kb})$, and these 22 contigs should cover a total of $11.5 \mathrm{Mb}(525$ $\mathrm{kb} \times 22=11.5 \mathrm{Mb}$ ). The other 21 contigs, each of which spanned more than two DNA marker positions, could cover at least $34.2 \mathrm{cM}$ genetic distance in total. The covered distance would correspond to $9.3 \mathrm{Mb}$ in physical length, because 1 cM of our $1575 \mathrm{cM}$ genetic map could be estimated to be $273 \mathrm{~kb}$ from the genome size of 430 $\mathrm{Mb}(273 \mathrm{~kb} \times 34.2 \mathrm{cM}=9.3 \mathrm{Mb})$. Then, a total of $21 \mathrm{Mb}(11.5 \mathrm{Mb}+9.3 \mathrm{Mb})$ should be covered by all the YACs arranged on chromosome 6. Taking into consideration that the genetic distance of chromosome 6 was $130.4 \mathrm{cM}$, we estimate the size of chromosome 6 to be $36 \mathrm{Mb}(273 \mathrm{~kb} /$ $\mathrm{cM} \times 130.4 \mathrm{cM})$. Therefore, the YAC contigs formed in this study should cover about $60 \%$ of the length of chromosome $6(21 \mathrm{Mb} / 36$ $\mathrm{Mb} \times 100)$. By use of estimation via minimum overlaps of tentative arrays, another method, the 63 YACs with 350-kb inserts could cover $22 \mathrm{Mb}$
$(350 \mathrm{~kb} \times 63), 60 \%$ of the length of this chromosome.

Examination of the YAC contigs in region 2 (see Fig. 2) suggested that the order of DNA markers C709C, P56, P81, P128, and W475C was different from that of these markers on our previous linkage map. Re-examination for linkage analysis revealed that these markers were located in a marker-dense spot at $69.8 \mathrm{cM}$ (data not shown), as suggested by the physical mapping data. This formation could well establish marker order on the physical map.

RFLP markers for 16 loci failed to identify chromosome 6 YACs from our YAC library. In particular, DNA markers for the regions downstream of chromosome 6 close to one of the telomere regions could select no YACs. It is possible that repeated sequences near the telomere could prevent DNA fragments from being cloned by YACs. This result indicates that our library contains few or no clones covering these regions. The host yeast strain used to construct our YAC library, AB1380, is apt to miss some fragments in specific genomic regions containing repeated sequences (Kohno et al. 1994). However, there is no information about the structure of missing YAC clones on the regions of chromosome 6 . To cover such regions with DNAs and to know their structures, it is necessary to make other YAC libraries, such as those constructed with recombinantdeficient yeast host like rad52 mutants (Dunford et al. 1993; Kohno et al. 1994). Recently, cloning systems for large DNA fragments using E. coli, such as P1 phage (Sternberg 1990) and bacterial artificial chromosomes (Shizuya et al. 1992), have been developed. These systems could be effective ways to clone DNA fragments unstable in yeast hosts.

Figure 2 YAC contigs on rice chromosome 6. The chromosome is shown in four parts from the upper end to the bottom end. The vertical bars on the right side of each diagram represent our high-density genetic map of chromosome 6 (Kurata et al. 1994b). Centimorgans shown beside arrows are genetic distances to adjacent DNA markers. Stretches with solid bars show the genetic distances covered by the YAC contigs. DNA markers are denoted between YAC contigs and the linkage maps. YACs are presented by thin bars on the left sides of the figures. Circles represent DNA markers located on those YACs. YACs including open rectangles were selected by coexisting DNA bands with RFLP markers, but not with the marker band itself. The sizes of the YACs, including filled circles, are shown in kb. The YACs labeled with clone numbers followed by (C) also carry DNA markers from a different location on the linkage map (candidate chimera). Gray bars between black bars and circles show the parts of YACs not recognized by the corresponding DNA markers (candidate deletion). The markers labeled with gray letters on the genetic map could not identify any YACs in this study. The markers labeled with underlined letters were not suitable for YAC screening because no bands in Nipponbare included multiple sequences or RAPD markers that were not converted to STS. 
There was one position on which 19 DNA markers were mapped together in the middle of region 2. However, YAC clones selected and arrayed by DNA markers in this position formed eight separate contigs. The physical distance of this region was estimated to be more than $2 \mathrm{Mb}$, because at least eight YACs of $350 \mathrm{~kb}$ average insert length span the region. Y4836 carrying a 480$\mathrm{kb}-$-long insert covers $0.3 \mathrm{cM}$ from R1679 to C235 in region 2. In the region covered by Y4836, the physical distance corresponding to $1 \mathrm{cM}$ was estimated to be $1600 \mathrm{~kb}$. In contrast, the physical distance per $\mathrm{cM}$ around Y1891, which carries a $410-\mathrm{kb}$ insert and covers a length of $3.3 \mathrm{cM}$ from G200 to C1478 in region 1, would be $124 \mathrm{~kb}$. This information could be useful in the investigation of which structures cause the observed differences in physical length per $\mathrm{cM}$ in these regions.

Fifty-nine out of 125 RFLP markers hybridized with multiple DNA fragments in Southern hybridization analysis for Nipponbare genomic DNA. Several similar sequences of these markers appeared to be dispersed on different chromosomes in the rice genome. Some of these multiple-copy sequences can be mapped by linkage analysis, but we could not map the others. Using these markers, all of the YAC clones carrying similar sequences located on different chromosomes or at different positions can be identified at once. Sometimes, some of the multiple-copy DNA markers also can identify YAC clones carrying the unmapped sequences. These unmapped sequences are, therefore, expected to be useful for ordering YAC clones, with an increasing possibility of being mapped onto a physical map as YAC contig formation progresses.

In this study, we identified 216 clones on chromosome 6 from our YAC library containing about 7000 clones. Soon, we will finalize a new version of a high-density linkage map with more than 2000 DNA markers. Physical mapping work is in progress to cover the remaining $40 \%$ of chromosome 6. After identification of YAC clones with all DNA markers on the linkage map, including additionally mapped markers, the remaining nonselected YACs will be assigned to the chromosomes by mapping with their end- or subclones. Chromosome walking and fingerprinting will also help to fill the gap regions between contigs.

YAC clones and DNA markers used in this manuscript are available from the MAFF DNA bank operated by the Ministry of Agriculture, Forestry and Fisheries of Japan. Request forms and information about the markers (positions in the linkage map, Southern blot hybridization images of RFLP markers, DDBJ accession numbers of RFLP marker sequences, primer sequences of RAPD and STS markers, and so on) are available on the world wide web at: http://bank.dna.affrc. go.jp. These marker data have also been incorporated into the data base Rice Gene accessible on the web at: http://probe.nalusda.gov:8300/cgibin/browse/ricegenes. This Rice Gene data base is operated by Cornell University under USDA auspices.

\section{METHODS}

\section{YAC Library and DNA Markers}

A rice YAC library containing 6934 clones with $350 \mathrm{~kb}$ average insert length and covering six genome equivalents was constructed from cultured cells of Oryza sativa L. $c v$. Nipponbare, as described previously (Umehara et al. 1995). A total of 144 DNA markers, including RFLP, STS, and RAPD markers, had already been located on the rice linkage map of chromosome 6 and have been deposited in DDBJ (Data Bank of Japan) (Inoue et al. 1994; Kurata et al. 1994b; Monna et al. 1994, 1995; Monna et al. 1995). All of these DNA markers were used for screening the YAC library to select clones that harbor those sequences.

\section{Screening of YAC Clones with RFLP Markers}

Screening of the 6934 YAC clones on five high-density replica filters was done by colony hybridization with RFLP markers as described by Umehara et al. (1995), with the following modifications. High-density replica filters were treated with $10 \%$ SDS for 5 min, followed by $0.5 \mathrm{M} \mathrm{NaOH}$ / $1.5 \mathrm{M} \mathrm{NaCl}$ for $10 \mathrm{~min}$, and then twice neutralized in 500 $\mathrm{mm}$ Tris- $\mathrm{HCl}(\mathrm{pH} 7.5) / 1.5 \mathrm{M} \mathrm{NaCl}$ for $5 \mathrm{~min}$. These filters were then hybridized with each RFLP probe on chromosome 6. Whole yeast DNAs of all YAC clones hybridized with each RFLP marker were extracted, digested with endonucleases, and electrophoresed. Southern hybridizations with the same RFLP markers used for colony hybridization were done to confirm whether each YAC contained mapped bands on chromosome 6. Both colony and Southern hybridization were performed by use of an ECL system (Amersham) for signal detection.

\section{Screening of YAC Clones with STS Markers}

A screening system with three-step polymerase chain reactions (PCR) was used to isolate YAC clones with STS markers (Jones et al. 1994). In the first screening, a PCR reaction with each STS primer was done on the DNA mixtures of eight superpools, yeast host strain AB1380 and rice $c v$. Nipponbare. DNA was extracted from the superpools, each of which contained 846 YAC clones in nine 96-well microtiter plates, except for the 10 microtiter plates used 
for the 8th superpool (Green and Olson 1990). In the second screening, PCR was done under the same conditions using three-dimensional DNA pools: eight row pools ( $\mathrm{xA}-$ $\mathrm{xH}), 12$ column pools ( $\mathrm{y} 1-\mathrm{y} 12)$ and nine plate pools $(\mathrm{z} 1-\mathrm{z} 9$ for the 1st to 7th superpools, z1-z10 for the 8th superpool). The marker-harboring YAC clones were identified by detecting a specific PCR product after gel electrophoresis of the products of each reaction. To confirm the positive clones containing DNA markers, a third PCR reaction was done with the individual DNAs of candidate clones.

\section{Construction of a Physical Map with YAC Clones}

Those YAC clones confirmed to have a DNA marker sequence were arranged on the marker positions of our molecular linkage map. YACs carrying several neighboring DNA markers together were arrayed to encompass those markers (see Fig. 2). The order of multiple DNA markers mapped on the same position of the linkage map could be well resolved through YAC arrangement. The arrangement of such DNA markers is also shown in the present physical map.

\section{ACKNOWLEDGMENTS}

We thank Zi-Xuan Wang, Shoko Saji, Takayuki Momma, Wim Van Houten, Takanori Shimokawa, Katsuhiko Yoshino, Norio Sue, and Yuichi Katayose for valuable advice and collaboration, and are most grateful to Kaetsu Kobayashi and Koichi Hasegawa for encouragement. We also thank Yoshiaki Nagamura, Masahiro Yano, Lisa Monna, and Akio Miyao for providing information on DNA markers and expert advice, and Ilkka Havukkala for proofreading. We are also most grateful to two reviewers whose constructive comments substantially improved the manuscript. This work was supported by the Ministry of Agriculture, Forestry and Fisheries, Japan, and by the Japan Racing Association.

A total of 144 DNA markers, including RFLP, STS, and RAPD markers, had already been located on the rice linkage map of chromosome 6 and have been deposited in DDBJ (Data Bank of Japan).

The publication costs of this article were defrayed in part by payment of page charges. This article must therefore be hereby marked "advertisement" in accordance with 18 USC section 1734 solely to indicate this fact.

\section{REFERENCES}

Ahn, S.N., J.A. Anderson, M.E. Sorrells, and S.D. Tanksley. 1993. Homoeologous relationships of rice, wheat and maize chromosomes. Mol. \& Gen. Genet. 241: $483-490$.

Ahn, S.N. and S.D. Tanksley. 1993. Comparative linkage maps of the rice and maize genomes. Proc. Natl. Acad. Sci. 90: $7980-7984$.

Arumuganathan, K. and E.D. Earle. 1991. Nuclear DNA content of some important plant species. Plant Mol. Biol. Rep. 9: 208-218.
Causse, M.A., T.M. Fulton, Y.G. Cho, S.N. Ahn, J. Chunwongse, K. Wu, J. Xiao, Z. Yu, P.C. Ronald, S.E. Harrington, G. Second, S.R. McCouch, and S.D. Tanksley. 1994. Saturated molecular map of the rice genome based on an interspecific backcross population. Genetics 138: 1251-1274.

Dunford, R., L. Vilageliu, and G. Moore. 1993. Stabilisation of a yeast artificial chromosome containing plant DNA using a recombination-deficient host. Plant Mol. Biol. 21: 1187-1189.

Dunford, R.P., N. Kurata, D.A. Laurie, T.A. Money, Y. Minobe, and G. Moore. 1995. Conservation of fine-scale DNA marker order in the genomes of rice and the Triticeae. Nucleic Acids Res. 23: 2724-2728.

Green, E.D. and M.V. Olson. 1990. Systematic screening of yeast artificial-chromosome libraries by use of the polymerase chain reaction. Proc. Natl. Acad. Sci. 87: 1213-1217.

Hauge, B.M., S. Hanley, J. Giraudat, and H.M. Goodman. 1991. Mapping the Arabidopsis genome. Symp. Soc. Exp. Biol. 45: 45-56.

Inoue, T., H.S. Zhong, A. Miyao, I. Ashikawa, L. Monna, F. Shuichi, N. Miyadera, Y. Nagamura, N. Kurata, T. Sasaki, and Y. Minobe. 1994. Sequence-tagged sites (STSs) as standard landmarkers in the rice genome. Theor. Appl. Genet. 89: 728-734.

Jones, M.H., O.S.A. Khwaja, H. Briggs, B. Lambson, P.M. Davey, J. Chalmers, C.-Y. Zhou, E.M. Walker, Y. Zhang, C. Todd, M.A. Ferguson-Smith, and N.A. Affara. 1994. A set of ninety-seven overlapping yeast artificial chromosome clones spanning the human $\mathrm{Y}$ chromosome euchromatin. Genomics 24: 266-275.

Kilian, A., D.A. Kudrna, A. Kleinhofs, M. Yano, N. Kurata, B. Steffenson, and T. Sasaki. 1995. Rice-barley synteny and its application to saturation mapping of the barley Rpg1 region. Nucleic Acids Res. 23: 2729-2733.

Kinoshita, T. 1993. Report of the committee on gene symbolization, nomenclature, and linkage groups. Rice Genet. Newsl. 10: 7-39.

Kohno, K., M. Wada, D. Schlessinger, M. D’Urso, S. Tanabe, T. Oshiro, and F. Imamoto. 1994. Stability of YACs containing ribosomal or RCP/GCP locus DNA in wild-type $S$. cerevisiae and RAD mutant strains. DNA Res. 1: 191-199.

Kurata, N., G. Moore, Y. Nagamura, T. Foote, M. Yano, Y. Minobe, and M. Gale. 1994a. Conservation of genome structure between rice and wheat. Bio/technology 12: 276-278.

Kurata, N., Y. Nagamura, K. Yamamoto, Y. Harushima, N. Sue, J. Wu, B.A. Antonio, A. Shomura, T. Shimizu, S.Y. Lin, T. Inoue, A. Fukuda, T. Shimano, Y. Kuboki, T. Toyama, Y. Miyamoto, T. Kirihara, H. Hayasaka, A. Miyao, L. Monna, H.S. Zhong, Y. Tamura, Z.-X. Wang, T. 


\section{UMEHARA ET AL.}

Momma, Y. Umehara, M. Yano, T. Sasaki, and Y. Minobe. 1994b. A 300 kilobase interval genetic map of rice including 883 expressed sequences. Nature Genet. 8: $365-372$.

Monna, L., A. Miyao, T. Inoue, F. Shuichi, M. Yamazaki, H.S. Zhong, T. Sasaki, and Y. Minobe. 1994.

Determination of RAPD markers in rice and their conversion into sequence tagged sites (STSs) and STS-specific primers. DNA Res. 1: 139-148.

Monna, L., A. Miyao, H.S. Zhong, T. Sasaki, and Y. Minobe. 1995. Screening of RAPD markers linked to the photoperiod-sensitivity gene in rice chromosome 6 using bulked segregant analysis. DNA Res. 2: 101-106.

Moore, G., M.D. Gale, N. Kurata, and R.B. Flavell. 1993. Molecular analysis of small grain cereal genomes: Current status and prospects. Bio/technology 11: 584-589.

Paterson, A.H., Y.-R. Lin, Z. Li, K.F. Schertz, J.F. Doebley, S.R.M. Pinson, S.-C. Liu, J.W. Stansel, and J.E. Irvine. 1995. Convergent domestication of cereal crops by independent mutations at corresponding genetic loci. Science 269: 1714-1718.

Saito, A., M. Yano, N. Kishimoto, M. Nakagawara, A. Yoshimura, K. Saito, S. Kuhara, Y. Ukai, M. Kawase, T. Nagamine, S. Yoshimura, O. Ideta, R. Ohsawa, Y. Hayano, N. Iwata, and M. Sugiura. 1991. Linkage map of restriction fragment length polymorphism loci in rice. Jpn. J. Breed. 41: 665-670.

Schmidt, R. and C. Dean. 1992. Physical mapping of the Arabidopsis thaliana genome. In Genome analysis, Vol 4: Strategies for physical mapping (ed. K.E. Davies and S.M. Tilghman), pp. 71-98. Cold Spring Harbor Laboratory Press, Cold Spring Harbor, NY.

Schmidt, R., J. West, K. Love, Z. Lenehan, C. Lister, H. Thompson, D. Bouchez, and C. Dean. 1995. Physical map and organization of Arabidopsis thaliana chromosome 4. Science 270: $480-483$.

Shizuya, H., B. Birren, U.J. Kim, V. Mancino, T. Slepak, Y. Tachiiri, and M. Simon. 1992. Cloning and stable maintenance of 300-kilobase-pair fragments of human DNA in Escherichia coli using an F-factor-based vector. Proc. Natl. Acad. Sci. 89: 8794-8801.

Sternberg, N. 1990. Bacteriophage P1 cloning system for isolation, amplification, and recovery of DNA fragments as large as 100 kilobase pairs. Proc. Natl. Acad. Sci. 87: 103-107.

Umehara, Y., A. Inagaki, H. Tanoue, Y. Yasukochi, S. Saji, Y. Otsuki, T. Fujimura, N. Kurata, and Y. Minobe. 1995. Construction and characterization of a rice YAC library for physical mapping. Mol. Breed. 1: 79-89.

Received March 18, 1996; accepted in revised form July 17, 1996. 


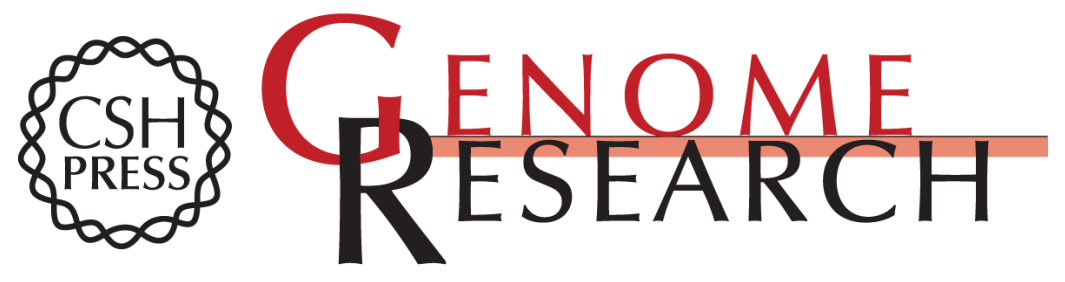

\section{An ordered yeast artificial chromosome library covering over half of rice chromosome 6.}

Y Umehara, H Tanoue, N Kurata, et al.

Genome Res. 1996 6: 935-942

Access the most recent version at doi:10.1101/gr.6.10.935

References This article cites 24 articles, 7 of which can be accessed free at:

http://genome.cshlp.org/content/6/10/935.full.html\#ref-list-1

\section{License}

Email Alerting Receive free email alerts when new articles cite this article - sign up in the box at the Service top right corner of the article or click here.

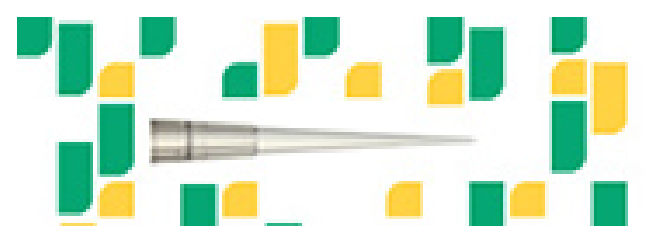

To subscribe to Genome Research go to: https://genome.cshlp.org/subscriptions 